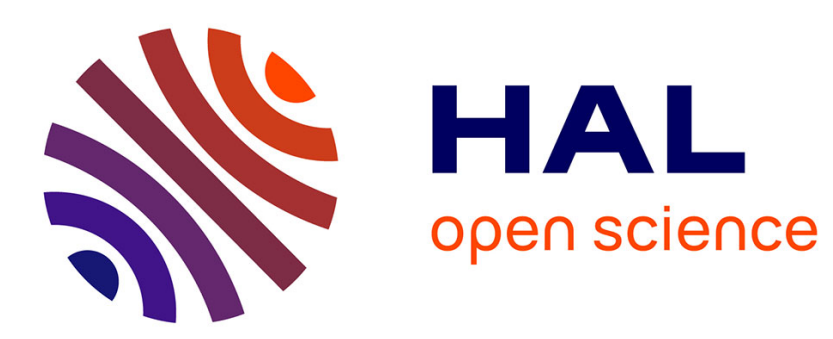

\title{
Michel Samson, Marseille en procès. La véritable histoire de la délinquance de Marseille
}

Tommaso Giuriati

\section{To cite this version:}

Tommaso Giuriati. Michel Samson, Marseille en procès. La véritable histoire de la délinquance de Marseille. Lectures, 2017. hal-02475448

\section{HAL Id: hal-02475448 \\ https://hal.science/hal-02475448}

Submitted on 12 Feb 2020

HAL is a multi-disciplinary open access archive for the deposit and dissemination of scientific research documents, whether they are published or not. The documents may come from teaching and research institutions in France or abroad, or from public or private research centers.
L'archive ouverte pluridisciplinaire HAL, est destinée au dépôt et à la diffusion de documents scientifiques de niveau recherche, publiés ou non, émanant des établissements d'enseignement et de recherche français ou étrangers, des laboratoires publics ou privés. 


\section{Michel Samson, Marseille en procès. La véritable histoire de la délinquance de Marseille}

\section{Tommaso Giuriati}

\section{Q OpenEdition}

Journals

Édition électronique

URL : http://journals.openedition.org/lectures/22688

ISSN : 2116-5289

Éditeur

Centre Max Weber

Ce document vous est offert par Centre national de la recherche scientifique (CNRS)

\section{cnrs}

\section{Référence électronique}

Tommaso Giuriati, « Michel Samson, Marseille en procès. La véritable histoire de la délinquance de Marseille», Lectures [En ligne], Les comptes rendus, 2017, mis en ligne le 18 avril 2017, consulté le 12 février 2020. URL : http://journals.openedition.org/lectures/22688

Ce document a été généré automatiquement le 12 février 2020.

(c) Lectures - Toute reproduction interdite sans autorisation explicite de la rédaction / Any replication is submitted to the authorization of the editors 


\title{
Michel Samson, Marseille en procès. La véritable histoire de la délinquance de Marseille
}

\author{
Tommaso Giuriati
}

1 Michel Samson, journaliste, est un spécialiste reconnu des mondes politiques marseillais: il a publié en 2005 Gouverner Marseille ${ }^{1}$ avec le sociologue Michel Peraldi et en 2015 Sociologie de Marseille ${ }^{2}$, toujours en collaboration avec Michel Peraldi et Claire Duport. Il est également l'auteur, avec le réalisateur Jean Louis Comolli, de Marseille contre Marseille ${ }^{3}$ : une longue série de documentaires très fouillés qui décrivent minutieusement les échéances électorales et les stratégies des acteurs qui en sont partie prenante. Cette connaissance est un des éléments qui fait la force de cet ouvrage, capable de mettre en question la relation entre justice et politique à Marseille, de façon profonde et précise. Il s'agit d'un ouvrage très instructif pour tous ceux qui s'intéressent aux phénomènes qui se déroulent dans le champ pénal, à Marseille et ailleurs. L'auteur a observé de nombreux procès qui ont eu lieu à Marseille afin de rendre compte de la complexité du travail des acteurs de la justice, notamment les magistrats du parquet et du siège, avant d'analyser quelques procès de grande ampleur médiatique.

2 Le livre est structuré comme un voyage, au cours duquel l'auteur nous emmène dans les méandres du palais de justice, des comparutions immédiates aux procès de grande ampleur où des membres du grand banditisme sont mis en cause, décrivant dans le détail le déroulement et les enjeux des procès. Il nous livre ainsi une analyse fine des interactions pendant les audiences, appuyées sur l'observation directe et sur la lecture des ORTC (ordonnances de renvoi devant le tribunal correctionnel), documents qui permettent de saisir le fond de l'affaire.

Dans l'introduction et le premier chapitre, l'auteur dresse une synthèse des idées reçues sur la délinquance marseillaise. Il réalise une brève recherche sur le mot " délinquance ", mettant en lumière qu'il s'agit d'une catégorie qui n'est pas propre à la justice (du moins en son sens générique), mais plutôt aux mondes politiques, journalistiques et, en partie, 
policiers, puis il évoque les productions littéraires et cinématographiques qui reprennent, relatent et enrichissent la réputation mondiale de «Marseille capitale [française] du crime [qui serait] gangrénée par une mafia qui en tiendrait les commandes » (p. 7).

4 On peut diviser le livre en deux parties. Dans la première, l'auteur passe en revue les différents types de procès que l'on peut observer au palais de justice (chapitres 2 à 6) en commençant par les comparutions immédiates, où les faits mineurs de délinquance sont jugés. Il s'agit ici très souvent de petite délinquance: vols à l'arrachée, violences familiales et de rue, revente d'objets volés, vente de drogues en faible quantité. S'ensuit une progressive montée en généralité par l'observation de procès d'escrocs qui se sont enrichis grâce à des montages financiers complexes et frauduleux, puis de ceux d'importants élus locaux, de trafiquants de drogues, d'auteurs de règlements de comptes. Dans la deuxième partie (chapitres 7 à 10), Michel Samson répertorie des procès où les sphères de la justice et de la politique se sont croisées. Parfois, des acteurs politiques ou syndicaux ont essayé de délégitimer un opposant dans une lutte politique en saisissant la justice pour qu'elle sanctionne des pratiques politiques pas toujours illégales. L'auteur relate efficacement la difficulté des magistrats à trancher sur des comportements qui sont aux marges du code pénal, lorsqu'ils s'aperçoivent que leur choix aura des retombées politiques évidentes. Il observe encore avec finesse comment le ministère de la Justice oriente la politique pénale du parquet à certains moments précis et délicats, par l'exemple lors des mouvements contre la loi Travail ou des débordements de hooligans pendant la coupe d'Europe de football de l'été 2016.

Pourtant, deux des propos du livre ne me semblent pas atteints et laissent le débat ouvert: démontrer qu'il n'y a pas une «spécificité marseillaise en matière de délinquance » (p. 175) et surtout démontrer qu'il n'y a pas une mafia à Marseille. Je pense par ailleurs que ces deux propos sont imbriqués, puisque l'éventuelle spécificité marseillaise serait en quelque sorte représentée par la présence d'un système mafieux. C'est donc l'existence (ou pas) de ce système mafieux qui fait débat actuellement, auquel des journalistes ont consacré plusieurs publications récentes ${ }^{4}$.

Choisir les audiences comme point d'observation est une démarche qui laisse dans l'ombre les étapes judiciaires en amont. Contrairement aux procès en comparution immédiate, les autres procédures pénales doivent être instruites. Il s'agit d'un processus parfois très long, qui relève de différents choix des acteurs (policiers et magistrats) qui y participent pour établir et qualifier les faits reprochés à la personne mise en examen.

7 La comparaison avec d'autres villes repose sur une semaine d'observation des audiences correctionnelles au tribunal de grande instance (TGI) de Bobigny, ce qui semble assez faible par rapport aux mois d'observation d'audiences au TGI de Marseille et à la cour d'assises des Bouches-du-Rhône. La question mafieuse, qui m'est chère parce que proche de mon sujet de recherche, reste quant à elle toujours en filigrane.

L'activité de la justice, au moins son activité "en audience", ne peut répondre à la question (à notre avis encore ouverte) de savoir si une mafia française existe ou pas, et s'il est possible que cette mafia française soit observable à Marseille. En effet, comme Michel Samson le rappelle à de nombreuses reprises, avocats généraux et juges du siège se mesurent uniquement au code pénal et au code de procédure pénale français. Or, le délit d'association mafieuse n'y est pas identifiés. Ainsi, les audiences ne peuvent pas mettre en lumière des systèmes mafieux, bien que des rapports de police aient soulevé cette hypothèse suite à des enquêtes sur un réseau d'affaires impliquant des politiques marseillais au début des années 2010. 
Pour aller plus loin dans le débat sur la présence des mafias en France, si les contributions théoriques sur les mafias sont principalement en langue italienne et anglaise, de nombreux travaux sont disponibles en français: on y découvre que les organisations mafieuses sont caractérisées par leurs fortes dotations en capital économique et social ${ }^{6}$ ainsi que par leur grande capacité à manier la violence, physique et symbolique ${ }^{7}$. Leurs relations avec les élites de leur région d'implantation sont complexes depuis le XIX ${ }^{e}$ siècle ${ }^{8}$, dans une alternance de rapports de force, et caractérisées par une relative porosité entre les deux champs'.

10 Je conseille donc ce livre à tous ceux qui, sociologues, juristes ou "simples citoyens", s'intéressent au fonctionnement de la justice pénale et à son administration en audience. La lecture est très agréable, et les observations lors des procès sont rigoureuses et instructives, informant un débat ouvert, qui a besoin de contributions comme Marseille en procès.

\section{NOTES}

1. Peraldi Michel, Samson Michel, Gouverner Marseille. Enquête sur les mondes politiques marseillais, Paris, La Découverte, 2005.

2. Michel Peraldi, Claire Duport, Michel Samson, Sociologie de Marseille, Paris, La Découverte, coll. «Repères Sociologie ", 2015 ; compte rendu de Lionel Francou pour Lectures: https:// lectures.revues.org/17939.

3. Comolli Jean-Louis, Samson Michel, Marseille contre Marseille. 12 ans de batailles électorales à Marseille et en Provence, 13 productions, 2005

4. Voir notamment Etchgoin Marie-France, Marseille le roman vrai, Paris, Éditions Stock, collection «Essais-Documents », 2016 et Monnier Xavier, Les nouveaux parrains de Marseille, Paris, Fayard, 2016.

5. Un « délit d'association de malfaiteurs aggravée par la méthode mafieuse » est par contre défini par l'article 416 bis du code pénal italien : l'association est mafieuse dès lors qu'en raison du lien associatif, ses membres obtiennent des bénéfices indus grâce à des relations d'intimidation, d'assujettissement et d'omerta imposées sur un territoire.

6. Sciarrone Rocco, « Réseaux mafieux et capital social », Politix, n 49, 2000, p. 35-56.

7. Champeyrache Clotilde, Sociétés du crime: un tour du monde des mafias, Paris, CNRS Éditions, 2007.

8. Lupo Salvatore, Histoire de la mafia des origines à nos jours, Paris, Flammarion, 2001.

9. Rizzoli Fabrice, "Pouvoirs et mafias italiennes. Contrôle du territoire contre état de droit ", Pouvoirs, n 132, 2010, p. 41-55. 


\section{AUTEUR}

\section{TOMMASO GIURIATI}

Doctorant en sociologie à l'Université Pasquale Paoli de Corse ; UMR LISA 6240, UMR LAMES 7305. 